\title{
Hospital standardised mortality rates should not be used to make interhospital comparisons
}

\author{
Martin McKee professor of European public health \\ London School of Hygiene and Tropical Medicine, London WC1H 9SH, UK
}

As Spiegelhalter notes, not knowing which countries are included in Brian Jarman's analysis makes it difficult to assess their validity. ${ }^{1}$ However, it is instructive to look at what researchers studying hospital standardised mortality rates (HSMRs) in other countries have concluded.

A Danish study that analysed 2007-11 data could not reconcile the substantial and often sudden changes in HSMRs with changes in quality of care, but the authors thought they were due to inherent noise in calculating HSMRs, such as variable quality of diagnostic coding. ${ }^{2}$

A Canadian paper found a lack of empirical evidence supporting the use of HSMRs in measuring reductions in preventable deaths. It also found that limitations in standardisation and differences in palliative care coding and place of death made inter-facility comparisons of HSMRs invalid, and concluded that these measures should not be viewed as an important indicator of patient safety or quality of care. ${ }^{3}$

In Australia, ${ }^{4}$ researchers decided that "Despite its apparent low cost and ease of measurement, the HSMR is currently not 'fit for purpose' as a screening tool for detecting low quality hospitals and should not be used in making interhospital comparisons."

One Dutch paper, ${ }^{5}$ noting improvements in hospital mortality, concluded "There can be many reasons ... including improved quality of care; however, it may also be due to, for instance, changes in hospital admission and discharge policies," while another, ${ }^{6}$ examining the effect of inflation of denominators by increased readmissions, found that models that did or did not adjust for this "produced substantially different HSMR outcomes."

These conclusions suggest that rather more thought might have been appropriate before publicising these findings on national television.

Competing interests: None declared.

Spiegelhalter D. Are you $45 \%$ more likely to die in a UK hospital rather than a US hospital? BMJ 2013;347:57775. (24 September.)

2 Gerdes LU, Poulstrup A. [Hospital standardised mortality ratios do not with certainty reflect the quality of patient care]. Ugeskr Laeger 2012;174:1590-4.

3 Penfold RB, Dean S, Flemons W, Moffatt M. Do hospital standardized mortality ratios measure patient safety? HSMRs in the Winnipeg Regional Health Authority. Healthc Pap 2008;8:8-24.

4 Scott IA, Brand CA, Phelps GE, Barker AL, Cameron PA. Using hospital standardised mortality ratios to assess quality of care-proceed with extreme caution. Med $J$ Aust 2011;194: 645-8

5 Ploemacher J, Israëls AZ, van der Laan DJ, de Bruin A. [Standardised in-hospital mortality decreasing over time]. Ned Tijdschr Geneeskd 2013;157:A5267.

6 Van den Bosch WF, Spreeuwenberg P, Wagner C. Variations in hospital standardised mortality ratios (HSMR) as a result of frequent readmissions. BMC Health Serv Res 2012;12:91.

Cite this as: BMJ 2013;347:f6155

๑ BMJ Publishing Group Ltd 2013 